Article

\title{
Comparison of Axial Magnetic Gears Based on Magnetic Composition Topology Differences
}

\author{
Sudirman Syam ${ }^{1, *(1)}$, Sudjito Soeparman ${ }^{2}$, Denny Widhiyanuriawan ${ }^{2}$ and Slamet Wahyudi ${ }^{2}$ \\ 1 Electrical Engineering Department, Science and Engineering Faculty, University of Nusa Cendana, \\ Kupang 85228, Indonesia \\ 2 Mechanical Engineering Department, Engineering Faculty, Brawijaya University, Malang 65145, Indonesia; \\ sudjitospn@yahoo.com (S.S.); denny_malang2000@yahoo.com (D.W.); slamet_w72@yahoo.co.id (S.W.) \\ * Correspondence: sudirman_s@staf.undana.ac.id; Tel.: +62-813-426-6234
}

Received: 20 March 2018; Accepted: 2 May 2018; Published: 4 May 2018

\begin{abstract}
This paper proposes a design and implementation of an axial type magnetic gear (MG) based on the composition of the magnetic arrangement. We report a quantitative comparison of two MG topologies with rectangular magnets arranged in series and parallel. Increased magnetic flux is done through magnetic circuit analysis and electrical circuit approach. Testing is done by using the rotation of a DC motor drive from 300-2600 rpm with a DC generator under load conditions. Measurement of load current and generator output power for both axial MG topologies are taken and analyzed. The results showed that the performance of an axial MG with the rectangular magnetic arrangement in parallel is better than that of a series arrangement. Based on the measured loading current of the two axial MG topologies, at generator rotation between 300-1300 rpm with 100, 200, and $300 \Omega$ resistance loads show the same load current. Conversely, after a DC generator rotation approaches $\frac{1}{2}$ of the maximum rotation (1300-2600 rpm) there is a significant increase in load current fluctuations. That is, with an increase of load currents occurring, the parallel magnetic topology shows an increase in load torque due to an increase of magnetic flux in the gear train magnets of the MG.
\end{abstract}

Keywords: parallel axis; NdFeB magnetic; design; electrical circuit

\section{Introduction}

Magnetic gears (MGs) are an alternative to replace mechanical gears as a transmission device that connects mechanical power with an electric load in high speed and high torque applications. MGs can easily replace mechanical gears while offering significant advantages of reduced acoustic noise, minimum vibration, maintenance free, better reliability, inherent overload protection, and physical isolation between the input and output shafts [1-3]. Compared to mechanical gears, there are no friction losses, heat losses, unwanted noise or vibration [4-7].

Parallel-axis MGs are one of the kinds of magnetic field transmissions that have been developed by Ikuta [8]. This type includes two different types of magnetic coupling: radial coupling and axial coupling. These MGs can be categorized into the category of MGs with closely spaced magnets. This gear type typically has a magnetic interaction between magnets on two or more axes. This technology uses two MGs covered with magnets on the surface. These magnets interact with each other and they create a driving force on the magnet wheel drive. The performance of this MG type has been studied $[9,10]$ by using the finite element analysis (FEA). Moreover, in $[11,12]$ the corresponding two-dimensional analytical calculation approach has been developed, exhibiting good agreement with the FEA results. Although the parallel-axis MGs are very simple, the results of analysis by researchers, 
both in analytical calculations and in finite element analysis show that this type of MG still has a low torque density [13].

On the other hand, MG can also achieve high efficiency, but high torque capability can be difficult to achieve unless careful consideration is made regarding the technology and MG design. That is why the torque density is the main problem for MG technology. The cost and amount of magnetic material are also connected. Recently there has been increasing concern about the price and supply of rare-earth elements. Although rare-earth MGs have better performance, fluctuating and expensive prices and limited reserves will increase the cost of MG manufacture, inhibiting further applications in MGs. In general, sector-shaped magnets were applied in the fabrication of MGs such as a parallel-axis MGs [14,15], radial MGs [9,10,13], permanent magnetic spur gears [12], and magnetic planetary gearboxes [16], which requires sufficient NdFeB magnetic material. Therefore, a rectangular permanent magnet that can replace sector-shaped magnets in the manufacture of MGs is an appropriate consideration.

Several techniques have been proposed to increase the MG torque, such as the use of magnetic material that has high energy capability. Rasmussen, et al. [17], and Atallah and Howe [18], focused their research on the type of magnet used in the manufacture of MGs prior to the NdFeB magnet type. The NdFeB magnet type has a very high magnetic strength and torque density compared to other magnetic types, with a torque density of $100 \mathrm{Nm} / \mathrm{L}$. Other topologies such as the worm and skew models have also been proposed by $[19,20]$. In [21], a new, better MG topology using a permanent magnetic cycloid was proposed. This MG topology can increase the torque density 2 times compared with previous MGs. However, all these topologies have very complex and complicated shapes.

Apart from work relating to this gear, surprisingly little attention appears to have been paid to axial MGs, despite the advantages of simpler construction compared to other MG topologies. In the axial MG structure, the rectangular magnet layers can be artfully integrated with a high-speed transmission to constitute an axial MG, which can reduce the use of rare-earth magnets while providing high torque density. Utilizing the simplicity of axial MG topologies, rectangular magnet layers can be advantageous in axial MG fabrication. A new technique has been proposed in this paper by varying the composition of the magnetic arrangement through the electrical circuit approach. Rectangular magnets are used in the manufacture of parallel axial type MGs. The purpose of this paper is to compare quantitatively the two MG-axis topologies based on their differences in magnetic composition when in series and parallel. Increased magnetic flux can be achieved by engineering the rectangular PM arrangement by applying a magnetic circuit analysis approach. To perform magnetic circuit analysis, the electric circuit approach can be used. The resistance (R) and reluctance $(\Re)$ are inversely proportional to the area, indicating that the increased surface area will result in a reduction in value and will increase the desired result in the form of current and flux. For long values, the opposite happens, i.e., the desired effect is reduced.

\section{Materials and Methods}

\subsection{NdFeb Rectangular Magnets}

It has been explained that the $\mathrm{NdFeB}$ magnet material has the highest magnetic torsion properties compared to other permanent magnets, such as ferrite, $\mathrm{AlNiCo}$, and $\mathrm{Sm}-\mathrm{Co}$. This type of magnet has the highest energy of all permanent magnets that are now practically used. The NdFeB magnet exhibits excellent performance in terms of size reduction, weight reduction, thinning and enhancing the efficiency of applied equipment. In this study, a rectangular magnetic measuring $10 \mathrm{~mm} \times 20 \mathrm{~mm} \times 1 \mathrm{~mm}$ was used in the manufacture of the magnetic gear.

\subsection{Acrylic Material}

Our prototype is different from the axial MGs that have been studied previously. The iron yoke has been replaced by using a disc made of acrylic (polymethyl methacrylate or PMMA). As discussed 
in the study of ironless coupling in [22], this design has a very small inertia and can be advantageous in many applications. The advantage of acrylic discs other than those mentioned earlier is that they can also eliminate the effect of magnetic saturation occurring on an iron yoke, and reduce the use of $\mathrm{NdFeB}$ magnets. Acrylic is an optically transparent amorphous thermoplastic, unaffected by moisture that offers a high strength-to-weight ratio. Chemically, this is a synthetic polymer of methyl methacrylate monomer. This material was developed in 1928 at several different laboratories by many chemists such as Chalmers, Röhm, and Bauer and was first marketed in 1933 by the Rohm and Haas Company. Common trade names of acrylic include Plexiglas, Lucite or Acrylate. Acrylic offers high light transmittance with a refractive index of 1.49 and can easily be formed with heat without losing optical clarity. Acrylic is easily sawed, drilled, milled, carved, and cut with a sharp carbide tool. It is also easy to bend at low temperatures, and it's available in extrusion and/or cast materials like sheets, rods, and tubes as well as special profiles. It is often preferred because of its good properties, easy handling and processing, and low-cost. Figure 1 shows the acrylic discs to be used in the manufacture of MGs.

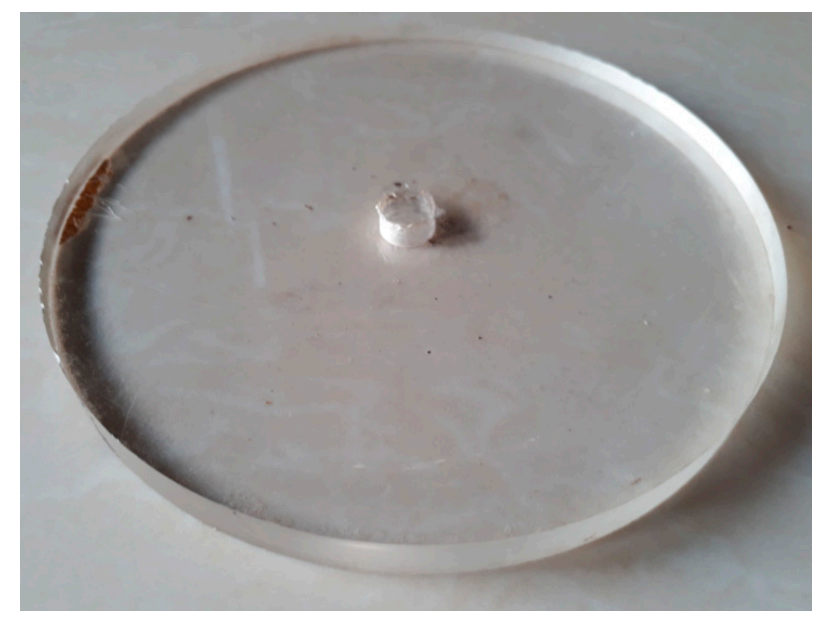

Figure 1. Acrylic disc.

\subsection{Test Procedures}

The general structure of the experimental bench is as illustrated in Figure 2. The main equipment includes a base board, DC regulator, DC Volt-meter, DC Ampere-meter, axial MG prototype, load resistance, DC motor, and DC generator, among which the base board is used for support. The DC motor is used as a prime mover with rated power at 25 watts and rated rotation speed of $2600 \mathrm{rpm}$. To set up the experiment, resistance loads of 100, 200, and $300 \Omega$ were applied with speeds varying from 0-2600 rpm. A tachometer was used to measure the rotation of the motor and generator. The input voltage of the drive motor uses a regulated DC voltage of $3-15 \mathrm{~V}$, while the measurement of the generator output voltage is measured based on the input voltage setting. The input and output currents are measured by variations of the generator output loading and motor rotation. Likewise, the rotations of both the motor and the generator are measured according to the DC input voltage setting of the motor. Figure 3 shows the prototype that has been created for experimental verification. The DC motor and DC generator used for testing the MG performance had the following specifications:

\footnotetext{
- $\quad \mathrm{V}_{\text {suplay }}:>30 \mathrm{~V}_{\mathrm{DC}}$

- $\quad$ Speed: $2750 \mathrm{rpm}$

- $\quad$ Torque: $10 \mathrm{kgm}$

- Weight: $1.5 \mathrm{~kg}$

- Current: $0.75 \mathrm{~A}$

- Power: $25 \mathrm{~W}$
} 


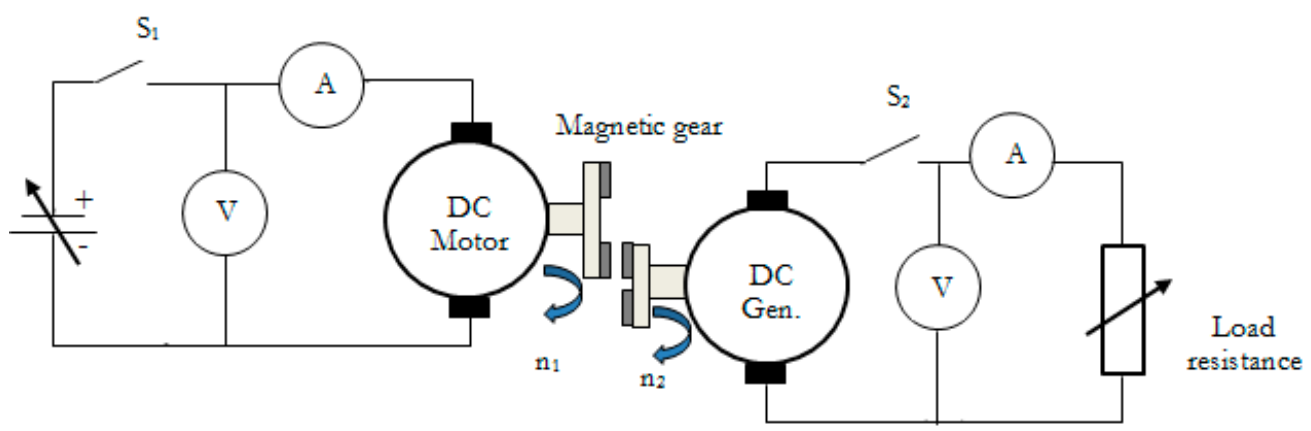

Figure 2. Experimental set up for measurement of load current and output voltage.

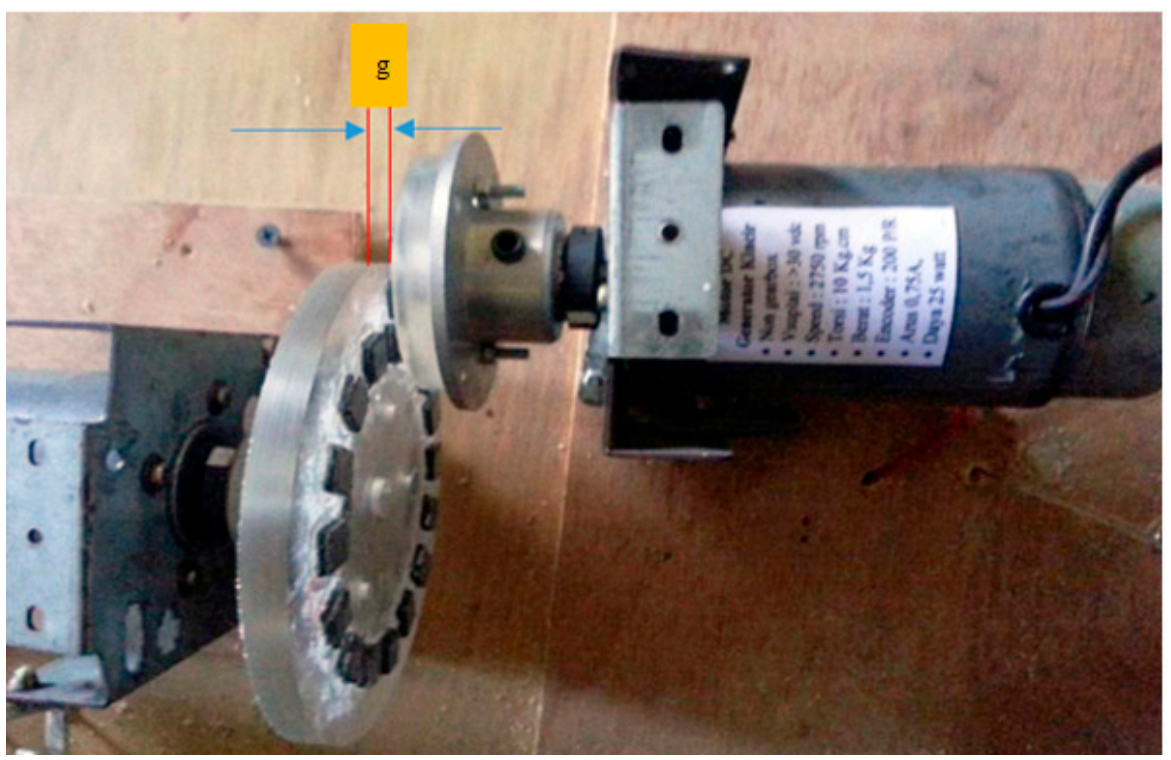

Figure 3. Axial MG prototype placed on the test bench $(\mathrm{g}=0.5 \mathrm{~mm})$.

\section{Results}

\subsection{Design Concept Development of the Axial MG}

\subsubsection{Geometry of the Gear}

Figure 4 shows a model of a parallel-axis MG with a conventional axial-coupling consisting of permanent magnets arranged in series $[8,23]$. It consists of two discs of different diameters separated by a small air gap and equipped with permanent magnets around it. A 2:1 gear ratio can provide a smaller disc rotation than with larger discs. Magnets are axially magnetized and arranged intermittently between the north and south poles. Soft-iron yoke is used to cover the flux. Through magnetic interaction, the torque generated on one of the discs is transferred through the air gap to the other disc. The magnets are coupled magnetically to each other, and when one magnet is rotated, it generates a torque into the second magnet causing it to spin. Synchronous coupling between magnets is a function of several variables, including the number of poles, material properties, dimensions, and air gap distance.

There are two types of synchronous coupling known as coaxial type and face type. The axial coupling is a face type coupling [24]. In a face type coupling, the equal-size rings carry alternating north and south poles. An important attraction force is created in the axial direction. The synchronous coupling can be achieved by using the power of attraction and the thrust of the permanent magnets. Both parts of the clutch are fitted with multi-pole settings. With the magnetic interaction, the two 
parts move at the same velocity, if using the same disk diameter. Rotation becomes higher when the size of the secondary disk is smaller and smaller, and on the contrary, the rotation is low when it is made larger.

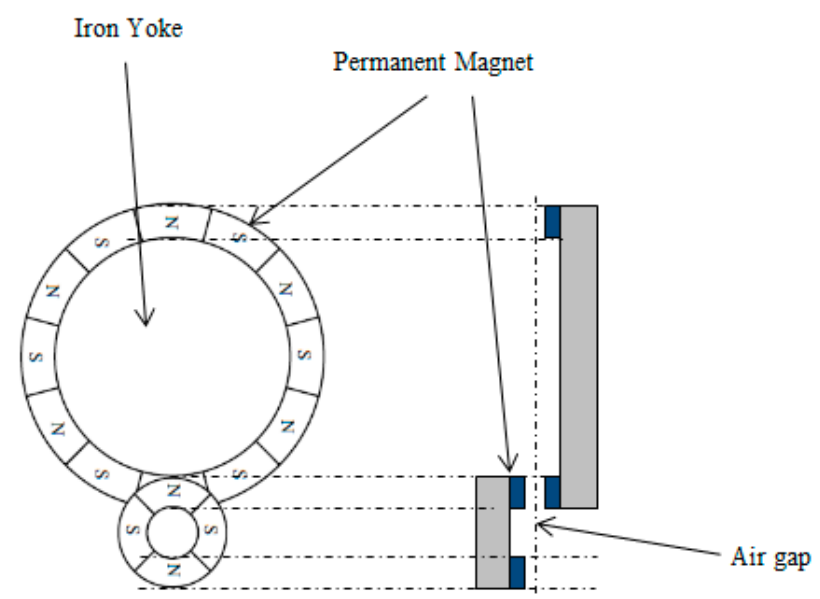

(a)

(b)

Figure 4. Parallel axis MG with axial-coupling type (a) front view; (b) side view.

\subsubsection{Concept Design}

The axial MG proposed in this paper refers to a conventional axial MG topology. Figure 5a shows a conventional topology using permanent magnet teeth arranged in series. Based on this design, it appears that the arrangement of the magnets is a closed circuit connected in series.

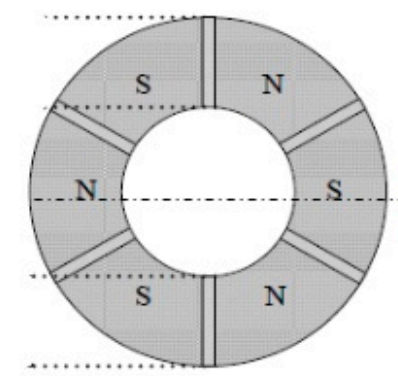

(a)

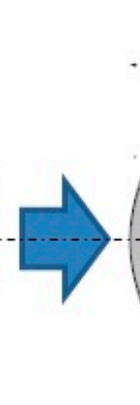

(b)

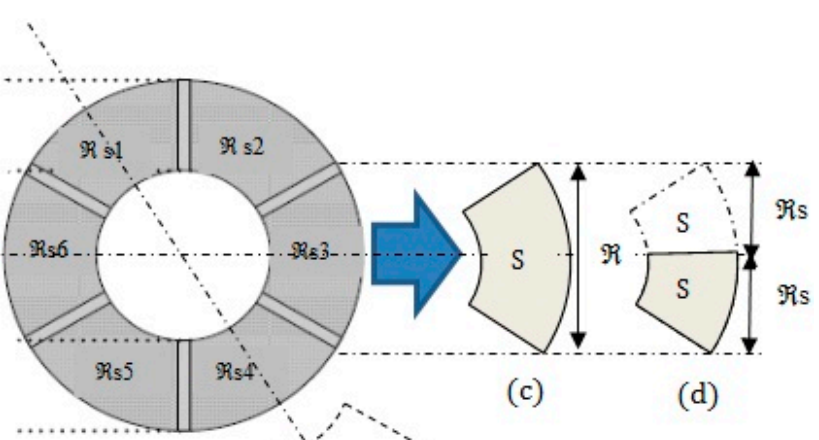

(b)

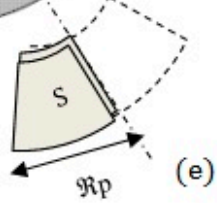

Figure 5. Analogies MG approach from magnet circuits into electrical circuits (a) Conventional MGs; (b) Analogies of MG gear into series reluctance; (c) Gear train magnets; (d) Pieces of series magnetic; (e) Parallel magnets.

Here, we approach the magnetic phenomenon using the analogy of electrical circuits. When using a circuit diagram, it appears that "electrical circuit" and "magnetic circuit" is equivalent. The mathematical relationship of the two circuits is described in the Appendix A. By analogy of electrical circuits, this type of MG can be analyzed as shown in Figure $5 b$. Figure $5 c$ is the shape of the magnetic teeth and appears to be a magnetic gear connected in series when it is cut into two parts (Figure 5d). In contrast, the roughly arranged magnetic teeth appear to be connected in parallel (Figure 5e). 


\subsection{Proposed MG Design}

Based on the concept shown in Figure 5, for example, six permanent magnets are arranged in such a way that it becomes a series circuit as shown in Figure 6a. Based on Ohm's law rule, the total reluctance is obtained using Equation (1):

$$
\Re \mathrm{s}_{\text {eries }}=\Re \mathrm{s}_{1}+\Re \mathrm{s}_{2}+\Re \mathrm{s}_{3}+\Re \mathrm{s}_{4}+\Re \mathrm{s}_{5}+\Re \mathrm{s}_{6}
$$

The value of the series reluctance ( $\Re \mathrm{s})$ is $6 \Re$

In contrast, Figure $6 \mathrm{~b}$ shows the arrangement of cuts from six magnetic to $\frac{1}{2}$ sections resulting in each cut of the magnetic bar changing the reluctance value to 0.5 from the previous value. Supposing it is rearranged into a circuit, then each magnetic rod assembled in parallel will result in a change in reluctance value again to 0.25 according to the following equation:

$$
\begin{gathered}
\frac{1}{\Re \mathrm{p}}=\frac{1}{\Re \mathrm{p} 1}+\frac{1}{\Re \mathrm{p} 2}+\frac{1}{\Re \mathrm{p} 3}+\frac{1}{\Re \mathrm{p} 4}+\frac{1}{\Re \mathrm{p} 5}+\frac{1}{\Re \mathrm{p} 6} \\
\frac{1}{\Re \mathrm{p} 1}=\left(\frac{1}{\Re \text { layer } 1}+\frac{1}{\Re \text { layer } 2}\right)
\end{gathered}
$$

or:

$$
\Re \mathrm{p} 1=\frac{\Re \text { layer } 1 \times \Re \text { layer2 }}{\Re \text { layer } 1+\Re \text { layer2 }}=\frac{0.5 \times 0.5}{0.5+0.5}=0.25 \Re
$$

The value of parallel reluctance ( $\Re \mathrm{p})$ is $1.5 \Re$.

From the electrical circuit analysis result it is clear that the magnetic arrangement in parallel will reduce the magnetic reluctance value. In accordance with the laws of magnetism and electricity, if the resistance or reluctance decreases, the current or magnetic flux will increase (Appendix A).

Based on this electrical circuit approach, the main purpose of the study is to develop an axial MG topology by arranging the gear train in parallel. The comparison of parameter specifications of the studied and proposed axial MGs is shown in Tables 1 and 2. Figures 7 and 8 shows a studied axial MG and proposed MG consisting of two discs with a 2:1 gear ratio and separated by an air gap, respectively. The disc used to install the layers of rectangular permanent magnets is made of acrylic material. The rectangular magnetic layers with parallel arrangement are mounted around the disc separated by a space. The space between the magnetic teeth of the MG is also an air gap or energy gap. This air gap has a magnetic force line effect called permeability $(\mu)$. Permeability is the ability of an object to pass through a magnetic force line [25].

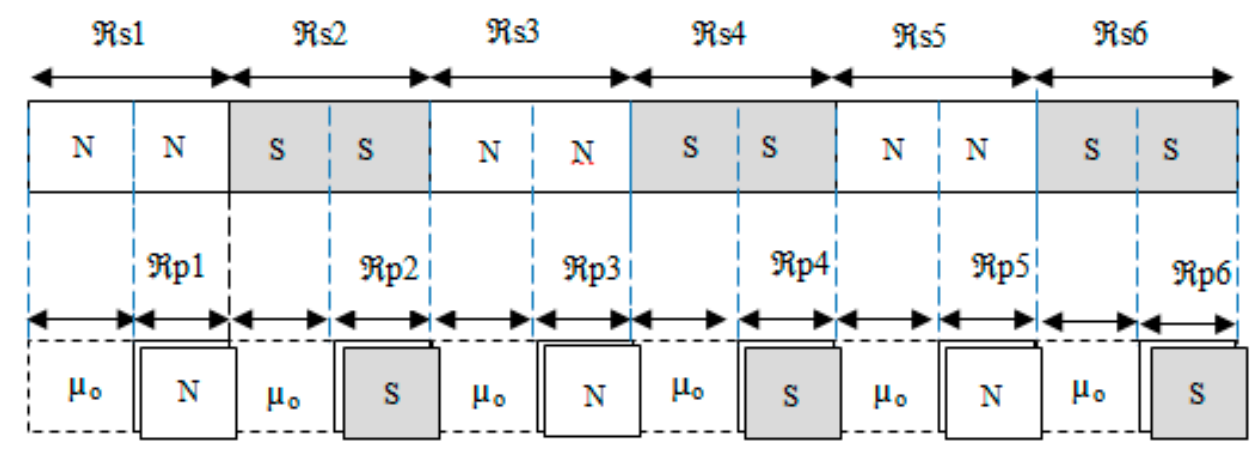

(a)

Figure 6. Analysis of magnetic circuits and electrical circuits: (a) series reluctances; (b) parallel reluctance. 
Table 1. Parameters of conventional axial MGs studied.

\begin{tabular}{clc}
\hline Symbol & \multicolumn{1}{c}{ Quantity } & Value \\
\hline $\mathrm{R}_{1 \mathrm{~d}}$ & Inner radius, drive magnets $(\mathrm{mm})$ & 40 \\
$\mathrm{R}_{2 \mathrm{~d}}$ & Outer radius, drive magnets $(\mathrm{mm})$ & 50 \\
$\mathrm{R}_{3 \mathrm{~d}}$ & Outer radius of the acrylic yoke, drive magnets $(\mathrm{mm})$ & 60 \\
$\mathrm{R}_{1 \mathrm{~s}}$ & Inner radius, source magnets $(\mathrm{mm})$ & 15 \\
$\mathrm{R}_{2 \mathrm{~s}}$ & Outer radius, source magnets $(\mathrm{mm})$ & 25 \\
$\mathrm{R}_{3 \mathrm{~s}}$ & Outer radius of the acrylic yoke, source magnets $(\mathrm{mm})$ & 30 \\
$\mathrm{~g}$ & Length of air gap (mm) & 0.5 \\
$\mathrm{t}$ & Magnets thickness $(\mathrm{mm})$ & 1 \\
$\mathrm{~h}$ & Magnets height (mm) & 10 \\
$\mathrm{~L} 1$ & Outer magnet length (mm) & 20 \\
$\mathrm{~L} 2$ & Inner magnet length (mm) & 18 \\
$\mathrm{~N}_{\mathrm{d}}$ & Number of pole pairs (source magnets) & 16 \\
$\mathrm{~N}_{\mathrm{s}}$ & Number of pole pairs (drive magnets) & 8 \\
$\mathrm{Br}$ & Remanence of the PMs & \\
\hline
\end{tabular}

Table 2. Parameters of the proposed axial MG.

\begin{tabular}{clc}
\hline Symbol & \multicolumn{1}{c}{ Quantity } & Value \\
\hline $\mathrm{R}_{1 \mathrm{~d}}$ & Inner radius, drive magnets $(\mathrm{mm})$ & 40 \\
$\mathrm{R}_{2 \mathrm{~d}}$ & Outer radius, drive magnets $(\mathrm{mm})$ & 50 \\
$\mathrm{R}_{3 \mathrm{~d}}$ & Outer radius of the acrylic disk, drive magnets $(\mathrm{mm})$ & 60 \\
$\mathrm{R}_{1 \mathrm{~s}}$ & Inner radius, source magnets $(\mathrm{mm})$ & 15 \\
$\mathrm{R}_{2 \mathrm{~s}}$ & Outer radius, source magnets $(\mathrm{mm})$ & 25 \\
$\mathrm{R}_{3 \mathrm{~s}}$ & Outer radius of the acrylic disk, source magnets $(\mathrm{mm})$ & 30 \\
$\mathrm{G}$ & Length of air gap $(\mathrm{mm})$ & 0.5 \\
$\mathrm{~T}$ & Magnets thickness $(\mathrm{mm})$ & 2 \\
$\mathrm{H}$ & Magnets height $(\mathrm{mm})$ & 10 \\
$\mathrm{~L} 1$ & Outer magnet length (mm) & 10 \\
$\mathrm{~L} 2$ & Inner magnet length (mm) & 8 \\
$\mathrm{~N}_{\mathrm{d}}$ & Number of pole pairs (source magnets) & 16 \\
$\mathrm{~N}_{\mathrm{s}}$ & Number of pole pairs (drive magnets) & 8 \\
$\mathrm{Br}$ & Remanence of the PMs & \\
\hline
\end{tabular}

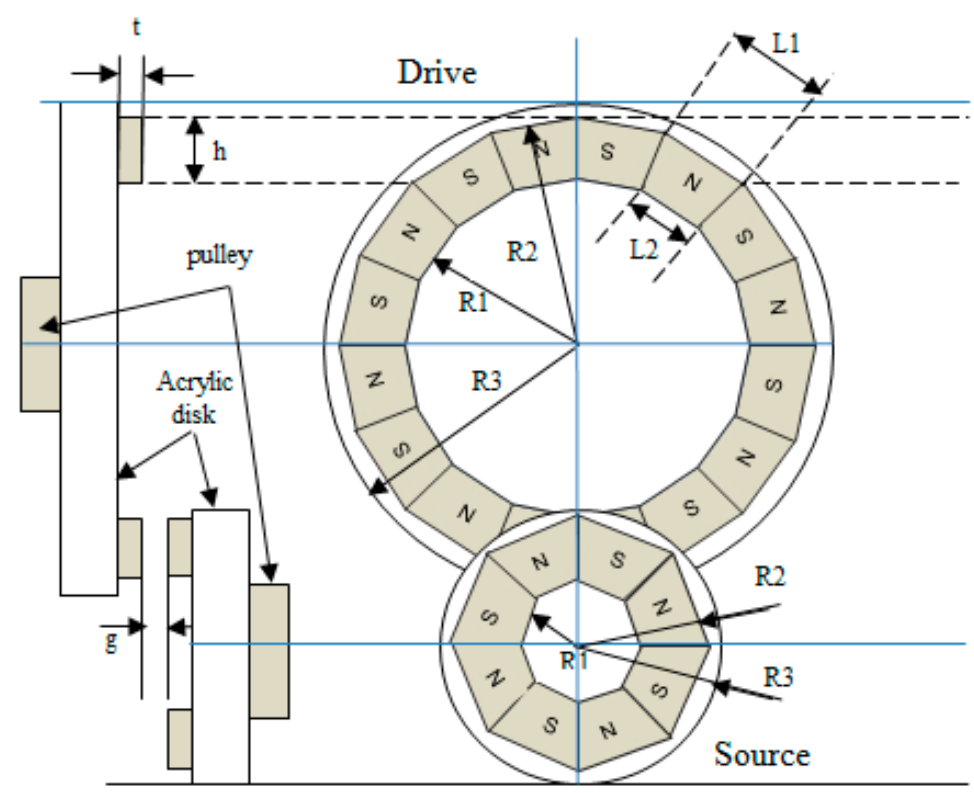

Figure 7. Geometry of a conventional axial MG studied with a gear ratio 2:1. 


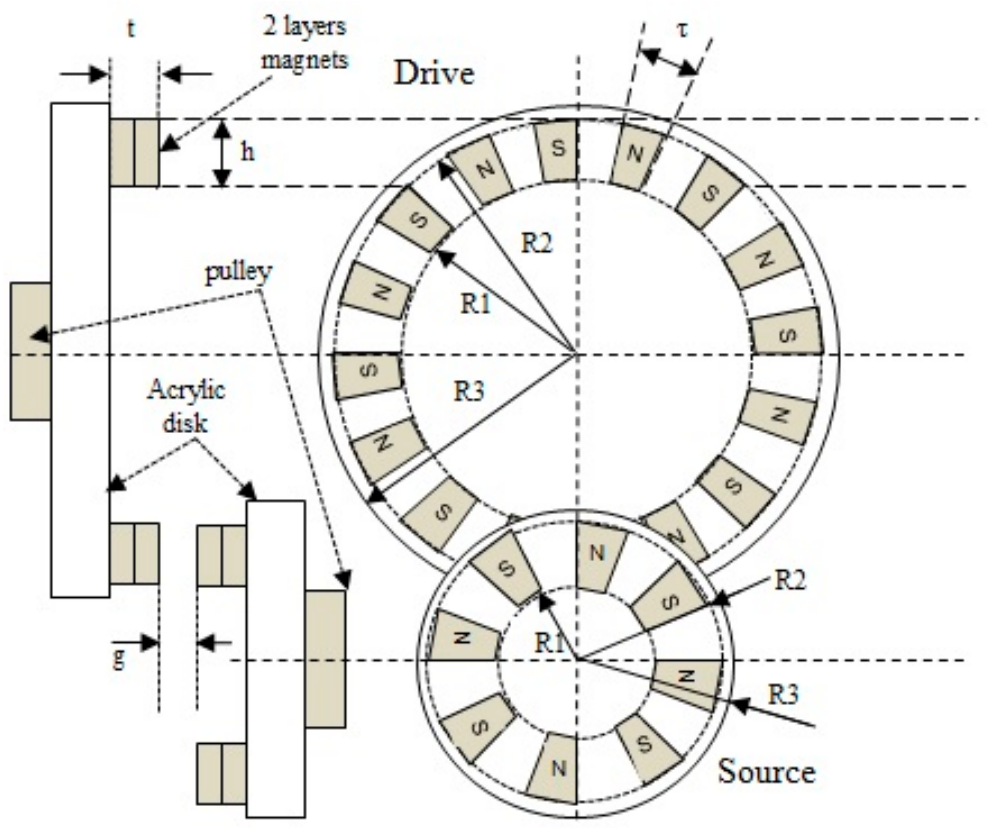

Figure 8. Geometry of proposed axial MG.

\subsection{Magnetic Flux Measurement}

In this paper, two MG topologies have been tested. One is an MG that uses a gear train arranged in series (conventional) which is similar to the previous MG design. Another magnetic gear uses the gear train proposed in this study. Figure 9 shows one example of the magnetic flux measurement results of a rectangular magnet obtained in a local market. The modification of the rectangular magnet to be used as MGs has also been measured as in Figure 10.

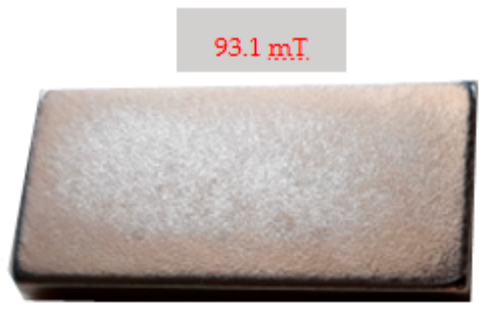

(a)

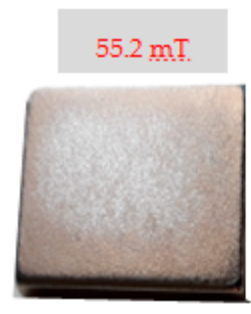

(b)

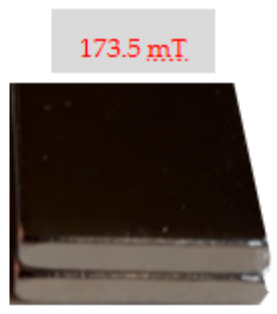

(c)

Figure 9. Measurements of magnetic flux (a) rectangular magnet; (b) $\frac{1}{2}$ piece of a rectangular PM of (a); (c) parallel piece of magnet.

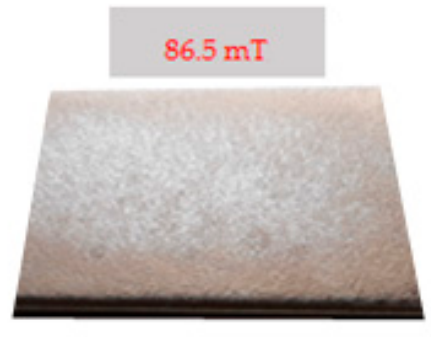

(a)

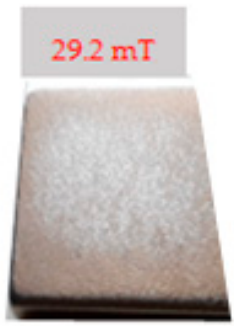

(b)

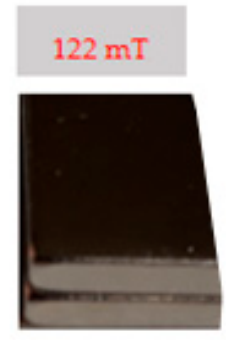

(c)

Figure 10. Measurements magnetic flux of modified magnetic rods (a) modified magnetic rod forms; (b) pieces of $\frac{1}{2}$ modified magnetic rods of (a); (c) parallel pieces of magnetic rods. 
Based on Equations (1) and (2) we have verified the comparison of other magnetic flux measurements using a Teslameter as shown in Tables 3 and 4.

Table 3. Results of magnetic flux measurements for primary MG.

\begin{tabular}{cccc}
\hline \multirow{2}{*}{ Magnet No. } & Series (1 Layer) & Parallel (2 Layers) & Notes \\
\cline { 2 - 4 } & $\mathbf{m T}$ & $\mathbf{m T}$ & \\
\hline 1 & 93.1 & 173.5 & $\mathrm{~N}$ \\
2 & 94.3 & 173.5 & $\mathrm{~S}$ \\
3 & 95.5 & 157.6 & $\mathrm{~N}$ \\
4 & 95.1 & 199.2 & $\mathrm{~S}$ \\
5 & 110.2 & 175.4 & $\mathrm{~S}$ \\
6 & 93.6 & 169.5 & $\mathrm{~N}$ \\
7 & 95.4 & 183.3 & $\mathrm{~S}$ \\
8 & 98.4 & 177.7 & $\mathrm{~N}$ \\
9 & 101.2 & 139.2 & $\mathrm{~S}$ \\
10 & 95.6 & 177.1 & $\mathrm{~S}$ \\
11 & 97.7 & 191.2 & $\mathrm{~N}$ \\
12 & 75.8 & 178.4 & $\mathrm{~S}$ \\
13 & 92.3 & 180.5 & $\mathrm{~N}$ \\
14 & 90.1 & 176.3 & $\mathrm{~S}$ \\
\hline 15 & 98.8 & 160.4 & \\
\hline 16 & 104.2 & 190.3 & \\
\hline$\Sigma$ & 1531.3 & 2803.1 & 175.19 \\
\hline $\bar{x}$ & 95.71 & & \\
\hline
\end{tabular}

Table 4. Results of magnetic flux measurements for secondary MG.

\begin{tabular}{cccc}
\hline \multirow{2}{*}{ Magnet No. } & Series (1 Layer) & Parallel (2 Layers) & Notes \\
\cline { 2 - 4 } & $\mathbf{( m T )}$ & $\mathbf{( m T )}$ & \\
\hline 1 & 112.3 & 215.2 & $\mathrm{~N}$ \\
2 & 110.2 & 236.5 & $\mathrm{~S}$ \\
3 & 77.6 & 183.4 & $\mathrm{~S}$ \\
4 & 78.8 & 194.2 & $\mathrm{~N}$ \\
5 & 97.5 & 196.1 & $\mathrm{~S}$ \\
6 & 108.2 & 239.2 & $\mathrm{~N}$ \\
7 & 104.4 & 214.3 & $\mathrm{~S}$ \\
8 & 106.3 & 222.4 & \\
\hline$\Sigma$ & 795.3 & 1701.3 & \\
\hline $\bar{x}$ & 99.41 & 212.66 & \\
\hline
\end{tabular}

We have presented a brief history of the magnetic flux value differentials based on theoretical magnetic composition which is the main concern of this article. It is clear that the comparison between the theory and experiments measuring the magnetic flux shows a trend of nearly twice the value difference between the flux values of the series and parallel. So far, the primary disks with series and parallel arrangement have an average flux value of $95.71 \mathrm{mT}$ and $175.19 \mathrm{mT}$, respectively. Similar magnetic flux values were also obtained on a secondary disk of $99.41 \mathrm{mT}$ in series and $212.66 \mathrm{mT}$ in parallel.

\subsection{Experimental Results}

First of all, the input and output speeds are measured up to a maximum rotation of $2.600 \mathrm{rpm}$ (Figure 11). This shows that motor and generator rotations are synchronized in the absence of slip. Data measurements were performed for both axial MG gear topologies with the same rotation ranging 
from 300-2600 rpm with the same load from 100 to $300 \Omega$. The measured data are input current, the load current of a motor input voltage and generator output voltage.

Experimental results from the input and load currents of two MG axial topologies with rotations ranging from 300 to $2600 \mathrm{rpm}$ are shown in Figure 12. Figure 13 shows the ratio of load torque between the two axial MG topologies with varying loads. It can be seen that the modification of one rectangular magnet cut into two rods and arranged in parallel can improve the axial MGs performance proportional with increased load current generator. Testing with speed from $0-1300 \mathrm{rpm}$ for both topological magnetic gears obtained the same load current. However, since the generator has reached $\frac{1}{2}$ of the maximum speed, it shows the difference of load current from both MG topologies. That is, after the DC generator reaches speeds of 1300-2600 rpm, the load current with gear-train topology in parallel higher than in series. The increase of the load current is proportional to the increase in load torque due to the difference of magnetic flux in the gear-train arrangement in both axial MG topologies. This clearly shows the necessity to consider the effect of flux on the gear-train of axial MG. As a non-contact gear, it relies on the air gap magnetic field passing power, torque, strong and weak magnetic field intensity distribution of the air gap directing an impact on current density distribution and the size of the magnetic moment passed.

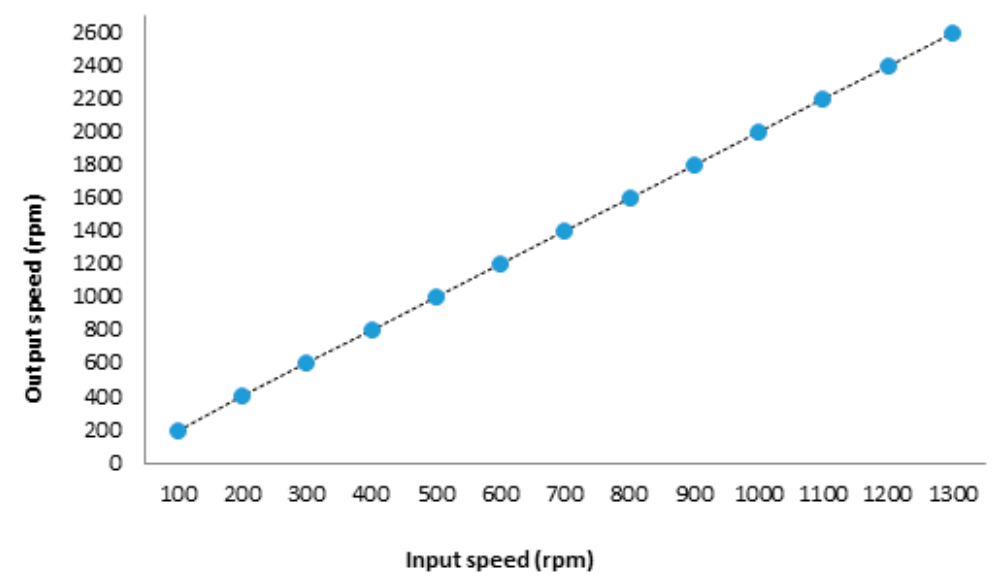

Figure 11. Input and output speeds.

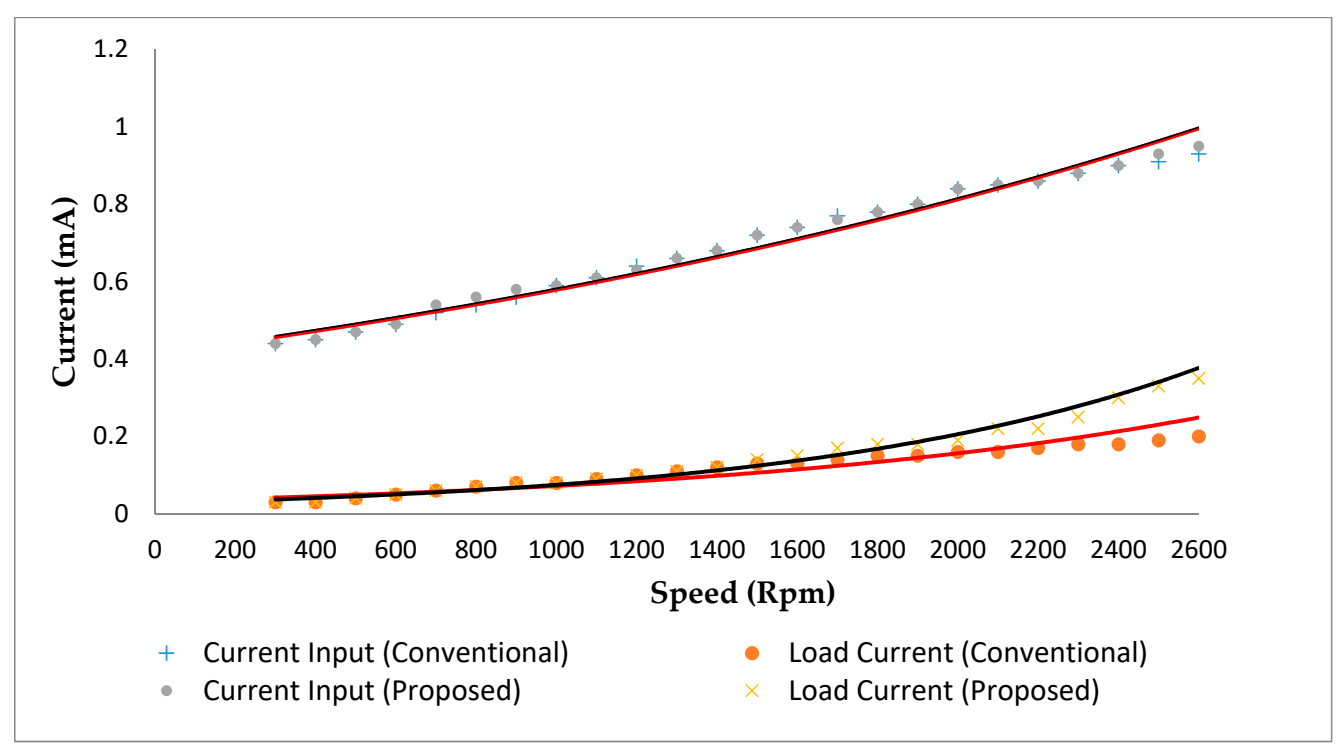

(a)

Figure 12. Cont. 


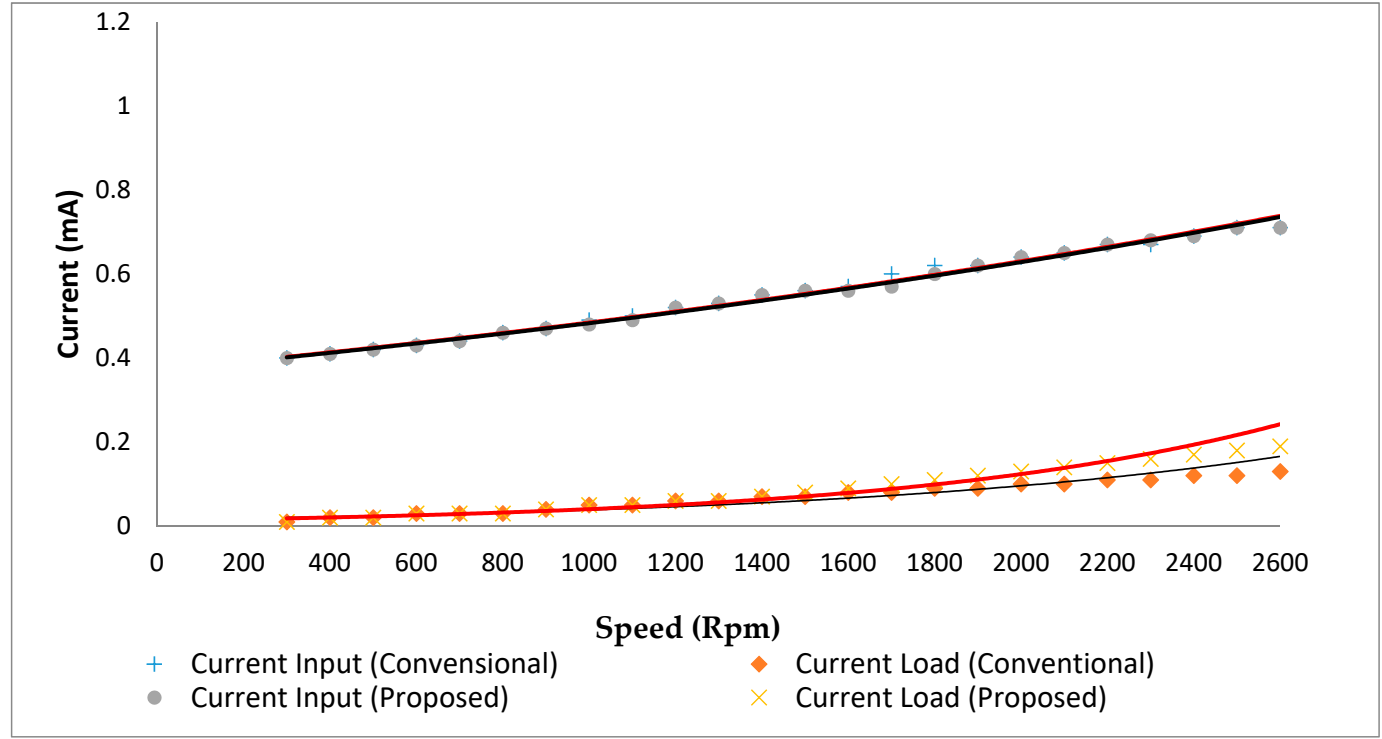

(b)

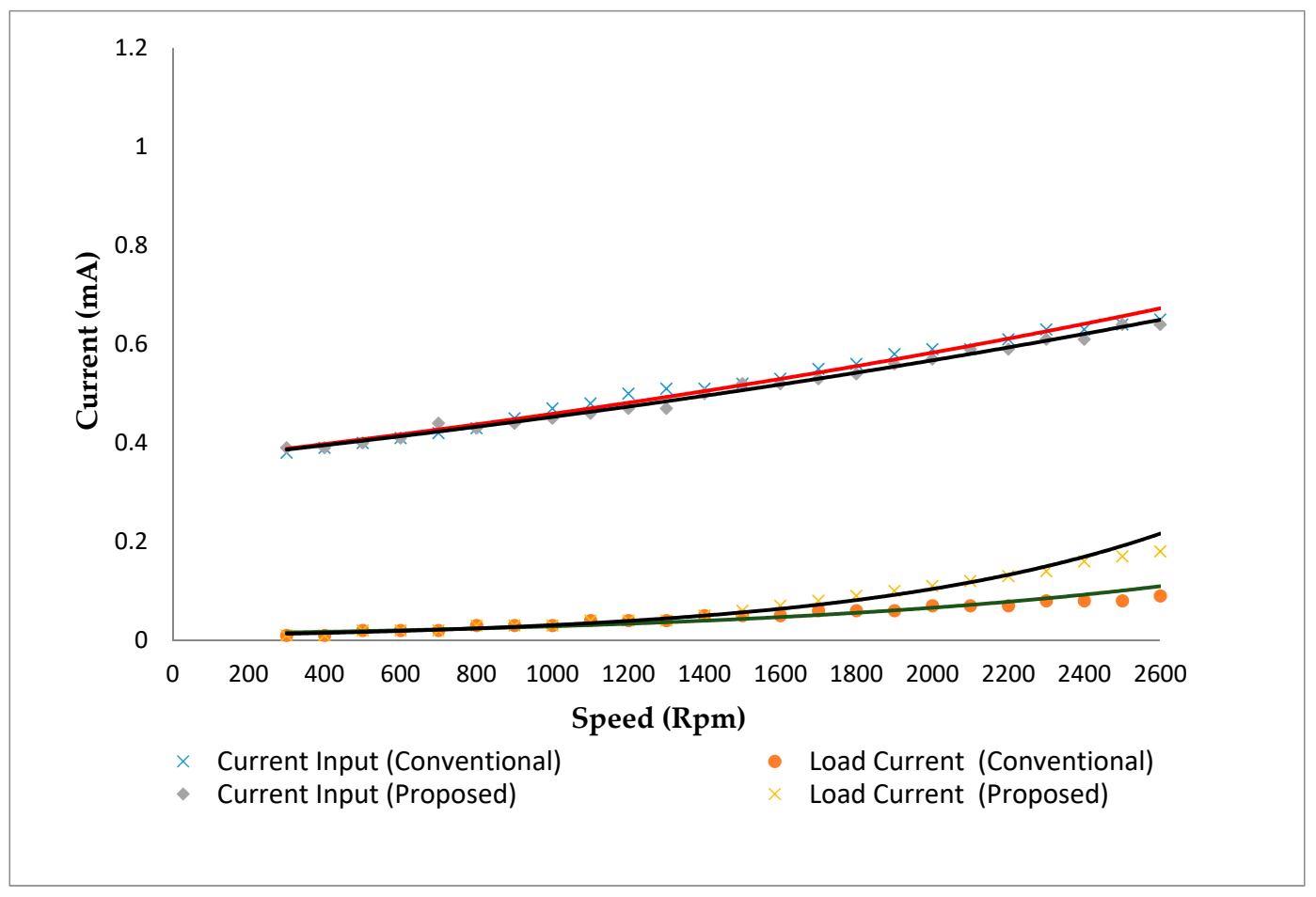

(c)

Figure 12. Comparison of input current and load current of axial topology arranged in series and parallel: (a) $100 \Omega$; (b) $200 \Omega$; (c) $300 \Omega$. 


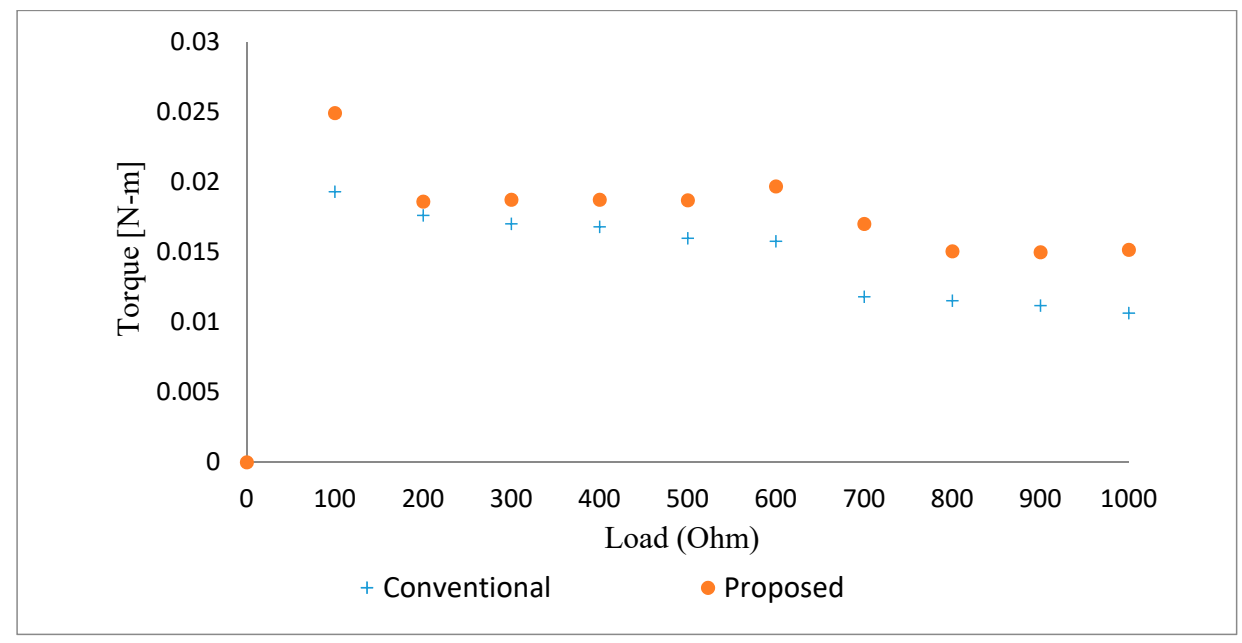

Figure 13. Comparison of load torque between two axial MG topologies with varying loads.

\section{Discussion}

Two different topologies using rectangular magnets have been tested. According to [26], compared to sector-shaped magnets, rectangular magnets have advantages of low-cost due to the size of materials and dimensions available. From a geometry standpoint, rectangular magnets have the advantages of standard product specifications, low production costs, and easy magnetization. However, two MGs meshed with rectangular magnets may cause interference or no magnetic contact to occur when the air gap length is insufficient [27]. Therefore, the modification of a single rectangular magnet cut into two rods and arranged in parallel based on the concept of Ohm's law has been done. The goal is to decrease the magnetic reluctance so that magnetic flux values can be increased.

Figures 7 and 8 show two axial MG topologies have been tested for obtaining measurable data, load current and generator output voltage. Figure 7 has a series MG arrangement that has been studied by previous researchers. Using the specifications given in Table 2 and the design of Figure $6 \mathrm{~b}$ with two parallel rods of magnets obtained from a single magnetic series strip, an axial MG topology is constructed as Figure 8. Modified magnetic teeth were arranged in parallel and mounted using adhesive glue on the acrylic dish. The advantage of using this acrylic material is to eliminate the effect of losses occurring on the iron yoke. In [28] it is clear that the iron losses occurring in iron yokes in the rotor and stationary rings are an important performance criterion in MGs. MGs with a 2:1 gear ratio are used to connect the low speed of a DC drive motor with a high-speed DC generator load applied. In addition, modification of one rectangular magnet cut into two parts and arranged in parallel can decrease the reluctance $(\Re)$ inversely with the increase of magnetic flux. It can also be seen from the results of magnetic flux measurements as shown in Figures 9 and 10. The increase of magnetic flux on each gear train also effects on increasing the torque of the axial MG.

\section{Conclusions}

In this paper, we discuss the comparison of two axial MG topologies based on the composition of the permanent magnet. The torque of the proposed MG topology is better than that of a conventional MG. The use of rectangular magnets is one of the alternatives to improve the axial MG performance. This has advantages of easy manufacture and simplicity and it does not require a special permanent magnet shape like any other MG topology. Using magnetic circuit analysis through an electrical circuit approach, we obtained the difference in magnetic flux by using a single rectangular permanent magnet of the same volume. Experimental results show that the use of MGs in the proposed axial topology may reduce the use of $\mathrm{NdFeB}$ magnets. The maximum torque load is measured $24.9 \times 10^{-3}(\mathrm{Nm})$ at $2600 \mathrm{rpm}$ rotation speed for proposed axial MG, while for the conventional MG type it is $19.3 \times 10^{-3}(\mathrm{Nm})$. 
Author Contributions: Conceptualization, Sudirman Syam and Soedjito Soeparman; Methodology, Sudirman Syam and Denny Widhiyanuriawan; Validation, Sudirman Syam, Soedjito Soeparman, Denny Widhiyanuriawan and Slamet Wahyudi; Investigation, Sudirman Syam; Resources, Sudirman Syam; Data Curation, Sudirman Syam; Writing-Original Draft Preparation, Sudirman Syam; Writing-Review \& Editing, Sudirman Syam; Visualization, Sudirman Syam and Slamet Wahyudi; Supervision, Soedjito Soeparman; Project Administration, Sudirman Syam; Funding Acquisition, Sudirman Syam.

Acknowledgments: The authors would like to acknowledge the support of the Laboratory of Electrical Engineering, University of Nusa Cendana-Kupang and scholarship support from the Ministry of Research Technology and Higher Education.

Conflicts of Interest: The authors declare no conflict of interest.

\section{Appendix Basic Approach of Comparison of a Magnetic Circuit and Electrical Circuit}

Figure A1 shows the equivalents of "electrical circuit" and "magnetic circuit". This is one approach that can be used to help provide an overview of magnetic phenomena with electrical circuit analogy. When using circuit diagrams, it appears that "electrical circuits" and "magnetic circuits" are equivalent. Therefore the mathematical relationships in both circuits must be similar. Based on Figure A1, there is some similarity/equality of parameters between electrical circuits and magnetic circuits as given in Table A1. The magneto-motive force ( $\mathrm{mmf}$ ) of an $\mathrm{N}$-turn current-carrying coil is given by:

$$
m m f=N I
$$

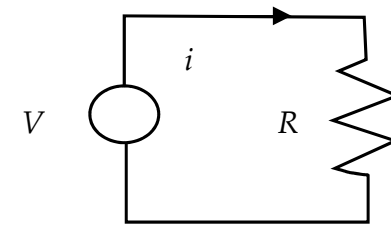

(a)

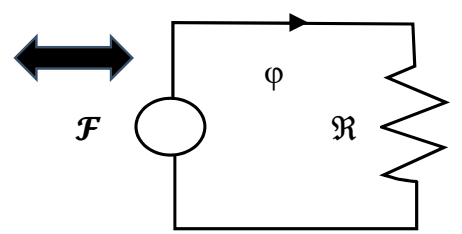

(b)

Figure A1. (a) Equivalent electrical circuits and (b) magnet circuit analogies.

Table A1. Analogous electrical and magnetic circuit quantities.

\begin{tabular}{cccc}
\hline Electric Circuit & Units & Magnetic Circuit & Units \\
\hline Voltage $(V)$ & Volt & Magneto-motive force $F=N I$ & Amp-turns \\
Current $(I)$ & Ampere & Magnetic flux $(\varphi)$ & Webers Wb \\
Resistance $(\mathrm{R})$ & Ohm & Reluctance $(\Re)$ & Amp-turns $/ \mathrm{Wb}$ \\
Conductivity $(1 / \rho)$ & Mho & Permeability $(\mu)$ & $\mathrm{Wb} / \mathrm{A}$-t-m \\
Current density $(J)$ & $\mathrm{A} / \mathrm{m}^{2}$ & Magnetic flux density $(B)$ & $\mathrm{Wb} / \mathrm{m}^{2}=$ teslas $\mathrm{T}$ \\
Electric field $(E)$ & Newton $/$ Coulomb $(\mathrm{N} / \mathrm{C})$ & Magnetic field intensity $(H)$ & $\mathrm{Amp}$-turn $/ \mathrm{m}$ \\
\hline
\end{tabular}

A current-carrying coil is the magnetic circuit equivalent to a voltage source in an electrical circuit. Therefore, magneto-motive force can be considered to be analogous to a source voltage. The reluctance of a path for magnetic flux $(\varphi)$, such as the iron bar shown in Figure A2, is given by:

$$
\Re=\frac{l}{\mu A}\left(\frac{A t}{W b}\right)
$$

Reluctance is analogous to resistance in an electrical circuit. When the bar is not straight, the length of the path is taken to be the length of the centerline. $l$ is therefore considered as the mean length of the path. The magnetic flux in a magnetic circuit is analogous to current in an electrical circuit although there is no flow like that of electric charge in the latter. Magnetic flux, reluctance and magneto-motive force $(\mathrm{mm} f)$ are related by:

$$
m m f=(\text { Reluctance } \times \varphi)
$$


This is similar to Ohm's Law:

$$
I=\frac{V}{R}
$$

Figure A2 shows the concept of the reluctance of a magnetic path which depends on the mean length, the cross-sectional area and the permeability of the material.

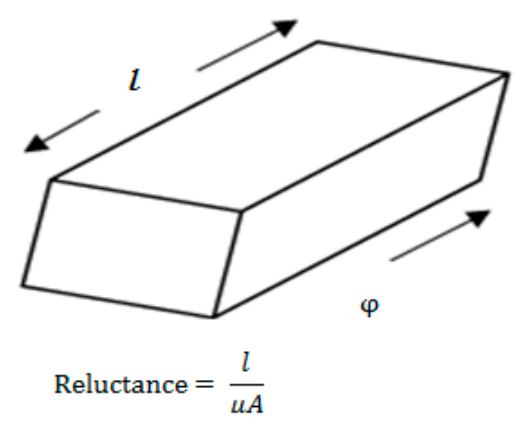

Figure A2. Concept of reluctance.

For the magnetic circuit, the desired effect is the flux $(\varphi)$, while the cause of the magnetic force $(\mathcal{F})$ is the outward force (pressure) required to define the magnetic flux line in the magnetic material. The resistance to the determination of flux $(\varphi)$ is the reluctance $(\Re)$, thus the value of the equation above is given by:

$$
\varphi=\frac{\mathcal{F}}{\Re}
$$

Furthermore, by using the "cause" analogy of Kirchhof's law of voltage, an equation can be obtained:

$$
\sum_{0} \mathcal{F}=0 \quad \text { (for magnetic circuit) }
$$

This equation states that the number of algebraic increments and the decrease of the magnetic motion force surrounding a closed loop on a magnetic circuit is zero. Thus, the amount of increase in the magnetic force is equal to the amount of decrease in the magnetic force around a closed loop. Equation (A7) is expressed as the Law of the Ampere Circuit. If this equation is applied to a magnetic circuit, the magnetic force source is denoted by:

$$
\mathcal{F}=N I(A t)
$$

\section{References}

1. Gouda, E.; Mezani, S.; Baghli, L.; Rezzoug, A. Comparative study between mechanical and magnetic planetary gears. IEEE Trans. Magn. 2011, 47, 439-450. [CrossRef]

2. Jian, L.; Chau, K.T.; Li, W.; Li, J. A novel coaxial magnetic gear using bulk HTS for industrial applications. IEEE Trans. Appl. Supercond. 2010, 20, 981-984. [CrossRef]

3. Li, W.; Chau, K.T.; Li, J. Simulation of a tubular linear magnetic gear using HTS bulks for field modulation. IEEE Trans. Appl. Supercond. 2011, 21, 1167-1170. [CrossRef]

4. Zhao, H.; Yang, Z.; Tian, J. Study on calculation method of the torque of permanent magnetic gears. Chin. J. Mech. Eng. 2001, 37, 66-70. [CrossRef]

5. Pakdelian, S.; Frank, N.W.; Toliyat, A.H. Principles of the Trans-Rotary Magnetic Gear. IEEE Trans. Magn. 2013, 49, 883-889. [CrossRef]

6. Musial, W.; Butterfield, S.; McNiff, B. Improving wind turbine gearbox reliability. In Proceedings of the European Wind Energy Conference, Milan, Italy, 7-10 May 2007.

7. Chau, K.T.D.; Zhang, J.; Jiang, Z.; Jian, L. Transient analysis of coaxial magnetic gears using finite elemenco-modeling. J. Appl. Phys. 2008, 103, 07F101. [CrossRef] 
8. Ikuta, K.; Makita, S.; Arimoto, S. Non-contact magnetic gear for micro transmission mechanism. In Proceedings of the IEEE Conference on Micro Electro Mechanical Systems, Nara, Japan, 30 January-2 February 1991; pp. 125-130.

9. Yao, Y.D.; Huang, D.R.; Lee, C.M.; Wang, S.J.; Chiang, D.Y.; Ying, T.F. Magnetic coupling studies between radial magnetic gears. IEEE Trans. Magn. 1997, 33, 4236-4238. [CrossRef]

10. Yao, Y.Y.D.; Huang, D.R.; Hsieh, C.C.; Chiang, D.Y.; Wang, S.J. Simulation study of the magnetic coupling between radial magnetic gears. IEEEE Trans. Magn. 1997, 33, 2203-2206. [CrossRef]

11. Furlani, E.P. A two-dimensional analysis for the coupling of magnetic gears. IEEE Trans. Magn. 1997, 33, 2317-2321. [CrossRef]

12. Jorgensen, F.T.; Andersen, T.O.; Rasmussen, P.O. Two dimensional model of a permanent magnet spur gear. In Proceedings of the Industry Application Conference, Kowloon, Hongkong, China, 2-6 October 2005; pp. 261-265.

13. Yao, Y.Y.D.; Huang, D.R.; Hsieh, C.C.; Chiang, D.Y.; Wang, S.J.; Ying, T.F. The radial magnetic coupling studies of perpendicular magnetic gears. IEEE Trans. Magn. 1996, 32, 5061-5063. [CrossRef]

14. Wang, R.; Furlani, E.P.; Cendes, Z.J. Design and analysis of a permanent magnet axial coupling using 3D Finite element Field computations. IEEE Trans. Magn. 1994, 30, 2292-2295. [CrossRef]

15. Yao, Y.D.; Chiou, G.J.; Huang, D.R.; Wang, S.J. Theoretical computations for the torque of magnetic coupling. IEEE Trans. Mag. 1995, 31, 1881-1884.

16. Chen, M.; Chau, K.T.; Li, W.; Liu, C. Development of non-rare-earth magnetic gears for electric vehicles. J. Asian Electr. Vehicles 2012, 10, 1607-1613. [CrossRef]

17. Rasmussen, P.O.; Andersen, T.O.; Jorgensen, F.T.; Nielsen, O. Development of a High-Performance Magnetic Gear. IEEE Trans. Ind. Appl. 2005, 41, 764-770. [CrossRef]

18. Atallah, K.; Howe, D. A novel high-performance magnetic gear. IEEE Trans. Magn. 2001, 37, 2844-2846. [CrossRef]

19. Kikuchi, S.; Tsurumoto, K. Design and characteristics of a new magnetic worm gear using permanent magnet. IEEE Trans. Magn. 1993, 29, 2923-2925. [CrossRef]

20. Kikuchi, S.; Tsurumoto, K. Trial construction of a new magnetic skew gear using permanent magnet. IEEE Trans. Magn. 1994, 30, 4767-4769. [CrossRef]

21. Joergensen, F.T.; Andersen, T.O.; Rasmussen, P.O. The cycloid permanent magnetic gear. IEEE Trans. Ind. Appl. 2008, 44, 1659-1665. [CrossRef]

22. Charpentier, J.; Lemarquand, G. Calculation of ironless Permanent Magnet couplings using semi numerical magnetic pole theory method. Int. J. Comput. Math. Electr. Electron. Eng. 2001, 20, 72-89. [CrossRef]

23. Li, X.; Chau, K.-T.; Cheng, M.; Hua, W. Comparison of magnetic-geared permanent-magnet machines. Prog. Electromagn. Res. 2013, 133, 177-198. [CrossRef]

24. Yonnet, J.-P. A new type of permanent magnet coupling. IEEE Trans. Magn. 1981, 17, 2991-2993. [CrossRef]

25. Gao, Q.; Wang, D.; Sheng, L. Application of field theory to air gap permanent magnet eddy current coupling. Adv. Sci. Technol. Lett. 2014, 73, 44-51.

26. Wu, Y.; Wang, C. Transmitted torque analysis of a magnetic gear mechanism with rectangular magnets. Appl. Math. Inform. Sci. 2015, 9, 1059-1065.

27. Wu, Y.; Tseng, W.; Chen, Y. Torque ripple suppression in an external-meshed magnetic gear train. Adv. Mech. Eng. 2013, 5, 178909. [CrossRef]

28. Jian, L.; Chau, K.T.; Gong, Y.; Jiang, J.Z.; Yu, C.; Li, W. Comparison of coaxial magnetic gear with different topologies. IEEE Trans. Magn. 2009, 45, 4525-4529.

(C) 2018 by the authors. Licensee MDPI, Basel, Switzerland. This article is an open access article distributed under the terms and conditions of the Creative Commons Attribution (CC BY) license (http://creativecommons.org/licenses/by/4.0/). 